\title{
Influence of Plyometric Training on the Level of Speed Ability with Changes of Direction in Ice Hockey
}

\author{
Marián Knechta' , Ivan Čillík', Jiří Zháněl² \\ ${ }^{1}$ Matej Bel University, Faculty of Arts, Banská Bystrica, Slovakia \\ ${ }^{2}$ Masaryk University, Faculty of Sports Studies, Brno, Czechia
}

\begin{abstract}
AIM: Speed skills are among the decisive factors in sports performance in ice hockey. Therefore, it is necessary to examine them in all age categories. Our goal was to determine the effect of plyometric exercises on the level of running and skating speed at $40 \mathrm{~m}$ with changes of direction in young hockey players aged $14-15$ years.

METHODS: The research group consisted of 33 ice hockey players (Male; age: $14.7 \pm 0.7$; height: $166.5 \mathrm{~cm} \pm 7.3$; weight: $53.4 \mathrm{~kg} \pm 6.9$ ) divided into two sets. Experimental group ( $n=18)$, and control group $(n=15)$. During 8 weeks, the players completed training units of general preparation and training units on ice, in the experimental set was added an experimental factor of plyometric exercises carried out according to the training protocol. Speed diagnostics consisted of the following two tests: running at $40 \mathrm{~m}$ with changes of direction and skating forward at $40 \mathrm{~m}$ with changes of direction.

RESULTS: Between the results of the tests in running speed and skating speed, significant differences were found both in the pretest and in the posttest between the experimental (EXP) and the control (KO) set in favor of the EXP set. Thus, the EXP set did not show the effect of plyometric exercises on improving the level of running speed and only a small effect on improving the level of skating speed.

CONCLUSION: The results of the quasi-experiment showed that the influence of plyometric exercises on the improvement of the level of running and skating speed of the players of the experimental group was not proven. In further research, it will be necessary to modify the training protocol and verify its application to comparable files.
\end{abstract}

Key words: running speed, skating speed, plyometric exercises, training protocol.

\section{INTRODUCTION}

Ice hockey is one of the most dynamic, fastest and toughest sports in the world, which places extreme demands on the athlete's muscle load. Speed skills are one of the most important factors in a hockey player's performance. Perič and Dovalil (2010), Boyl (2016), Owen and Dellal (2016), Jebavý and Hojka (2017) characterize speed skills as the ability to perform activities with maximum intensity resp. develop the maximum possible speed in the shortest possible time with a movement activity of up to 20 seconds, without almost any resistance. In ice hockey, speed manifestations are tied to specific motor skills, determined by skating and activity on ice. Tóth (2010), Joyce and Lewindon (2014), Skahan (2016) and others agree that a characteristic feature of the current development of world hockey is the process of its further intensification, i. increased pace of play, which leads to more performed individual game activities and game combinations. In this context, the development of speed skills is becoming even more important, which is one of the important factors in increasing the effectiveness of the hockey player's technical skills. The volume of performed intensive activity of the player increases, the action of the player takes place under increasing temporal and spatial pressure, which is one of the characteristic features of 
modern ice hockey. Plyometric training is often used to develop the explosive force of the lower limbs, which is needed in skating. Hansen and Kennelly (2017) say that the plyometry method is based on the principle of stretching and shortening. Its characteristic feature is the eccentric contraction caused by (rapid braking) and subsequently the fastest possible transition to the opposite direction, the so-called concentric contraction. At present, plyometry is widespread and used in almost all sports. Authors such as Lockwood and Brophey (2008) and Lee et. al. (2014), Haukali and Tjelta (2015), Deahlin, et. al (2017) examined plyometry in direct relation to the speed of skating. Chu (1998) argues that puberty is the fastest growing period, and therefore the best time to develop speed-strength skills in ice hockey players, who are increasingly in demand in today's hockey and players who do not have these qualities have no chance. to promote in an international forum. Also on the basis of the above research, in which the authors focused on plyometric exercises, we decided to do our research with players aged 14-15. Another reason is the fact that Slovak players in the youth categories lag behind their peers from hockey-developed countries in the speed of skating. The aim of the research was to determine the effect of plyometric exercises according to the selected training protocol on the level of running and skating speed at $40 \mathrm{~m}$ with changes of direction in young hockey players aged 14-15.

\section{METHODS}

\section{The research sample}

A total of 33 ice hockey players aged $14-15$ (male; age: $14.7 \pm 0.7$; height: $166.5 \mathrm{~cm} \pm 7.3$; weight: $53.4 \mathrm{~kg} \pm 6.9$ ) were involved in the research, divided into two subsets, the control group (KO) $(\mathrm{n}=15)$ and the experimental group (EXP) $(n=18)$ players. Both teams play the highest cadet competition in Slovakia (Top 14).

Table 1. Basic statistical characteristics of experimental and control set

\begin{tabular}{lcccccccccc}
\hline Variables/Groups & \multicolumn{4}{c}{ Experimental $(n=18)$} & \multicolumn{3}{c}{ Control $(n=15)$} & \multicolumn{2}{c}{$d$} & ES \\
& M & SD & Min. & Max. & M & SD & Min. & Max. & & \\
\hline Age (years) & 14.8 & 0.6 & 14.2 & 15.4 & 14.6 & 0.8 & 14.1 & 15.4 & 0.28 & small \\
Height $(\mathrm{cm})$ & 165.0 & 8.0 & 156 & 173 & 168.0 & 6.5 & 158 & 175 & 0.41 & small \\
Weight $(\mathrm{kg})$ & 52.6 & 7.2 & 45 & 65 & 54 & 6.6 & 48 & 69 & 0.20 & small \\
BMI & 19.5 & 2.1 & 17.4 & 21.6 & 19.1 & 3.5 & 15.6 & 22.6 & 0.14 & trivial \\
\hline
\end{tabular}

Explanation: $n=$ number of subjects; $\mathrm{M}=$ mean; $\mathrm{SD}=$ standard deviation; $d=$ effect size index; $\mathrm{ES}=$ effect size

\section{Procedure}

For the research, we chose a field two-group time-parallel model of the quasi-experiment type, in which it was not possible to randomly (randomize) assign the monitored objects to individual experimental conditions. Two sets of hockey players already existed before the experiment was set up, so it is a type of experiment of so-called non-equivalent groups requiring pretest and posttest of the experimental and control group. The research itself took place during the competition period from September 2019 to January 2020. The initial measurements of the experimental set took place on 16 September 2019 off-ice and on-ice. The initial measurements of the control group took place on September 23, 2019 off-ice and on-ice. This was followed by an 8-week experimental period. During the experimental period, the players of both groups completed training units on dry land and ice. The players in the experimental set completed 5 training units on ice 
per week for 60 minutes and one competitive match. The players in the control group completed 4 training units on ice per week in the range of 75 minutes and one competitive match. The training units of the general training were completed by the players in the experimental and control group 3 times a week in the range of 60 minutes. An experimental factor of plyometric exercises was added to the experimental set, which players performed twice a week in the range of 20-25 min before the training unit on the ice. After warming up, there was an experimental stimulus in the form of plyometric exercises in the form of circular training, where subjects completed exercises at 9 stations, each station had one to two subjects, exercises in three rounds with a total of 360-366 different reflections, one training session. unit with a load and rest interval of 1: 3 . Training methods on-ice were a similar nature in expermiental and control files according to the methodological guideline of SZLH.

Table 2. Training protocol of the experimental set

\begin{tabular}{|c|c|c|c|}
\hline Tuesday & & Thursday & \\
\hline Exercise name & $\begin{array}{l}\text { Number of } \\
\text { repetitions }\end{array}$ & Exercise name & $\begin{array}{l}\text { Number of } \\
\text { repetitions }\end{array}$ \\
\hline $\begin{array}{l}\text { Squats with jump and pole on the } \\
\text { shoulders }(16-20 \mathrm{~kg})\end{array}$ & 10 & Squat + lunge sideways + jump & 10 \\
\hline Star jumps on the tire $(40 \mathrm{~cm})$ & 15 & $\begin{array}{l}\text { Jumps to reproduction + preloading } \\
\text { with }(5 \mathrm{~kg}) \text { disc }\end{array}$ & 20 \\
\hline $\begin{array}{l}\text { Ascents on the tire }(40 \mathrm{~cm}) \text { with one } \\
\text { foot alternately }\end{array}$ & 20 & Side jumps on one leg & 20 \\
\hline $\begin{array}{l}\text { Jumping in a lunge with turning the } \\
\text { torso and arms with a ( } 3-5 \mathrm{~kg}) \text { disc }\end{array}$ & 10 & Jump on and off the crate $(40 \mathrm{~cm})$ & 12 \\
\hline Jumps over obstacles 4 pcs & 16 & $\begin{array}{l}\text { Hockey jump + vertical jump with } \\
(3-5 \mathrm{~kg}) \text { medicine ball }\end{array}$ & 12 \\
\hline $\begin{array}{l}\text { Jumps on one leg } \\
\text { Right } 5 \text {, Left } 5\end{array}$ & 10 & Jumps over obstacles 4 pcs sideways & 12 \\
\hline $\begin{array}{l}\text { Hockey jumps with folding }(3-5 \mathrm{~kg}) \\
\text { reel }\end{array}$ & 20 & $\begin{array}{l}\text { Obstacle jump }+ \text { side shift }+ \text { obstacle } \\
\text { jump }\end{array}$ & 10 \\
\hline Jumps with $180^{\circ}$ turn & 10 & Squat + jump on one leg, right 8 left 8 & 16 \\
\hline $\begin{array}{l}\text { Jump on the box }(40 \mathrm{~cm})-\text { jump off }- \\
\text { jump over the obstacle }(40 \mathrm{~cm})\end{array}$ & 10 & $\begin{array}{l}\text { The advantage of dumbbells to lunge } \\
\text { with }(16-20 \mathrm{~kg}) \text { bar }\end{array}$ & 10 \\
\hline Together & 360 & Together & 366 \\
\hline
\end{tabular}

Output measurements were performed in both sets under the same conditions as the input measurements. in experimental group 25.11.2019 and in control group 2.12.2019. This was followed by a post-experimental period, during which the players in both sets underwent the same training and match load as in the experimental period. The players of the experimental ensemble did not complete the experimental factor of the plyometric exercise. We performed post-experimental measurements 8 weeks after the end of the experimental period, under the same conditions as the previous measurements. In experimental group 20.1.2020 and in control group 27.1.2020.

\section{Research methods}

Performance in the non-standardized "run / skate test for $40 \mathrm{~m}$ with changes of direction" was determined using the following protocol: $10 \mathrm{~m}$ run / skate, $180^{\circ}$ turn, $20 \mathrm{~m}$ back / skate, $180^{\circ}$ turn, $10 \mathrm{~m}$ run / skate back ( Figure 1). The first test was performed off ice (running speed) and 
the second test was performed on ice (skating speed). It started from a standing start on its own initiative, while the player on the ice and off the ice had to cross one line with one foot, which indicated the length of the section. The players warmed up before each discipline, passing each test 2 times. In the evaluation, we recorded the better of the two experiments, the time was recorded using photocells.

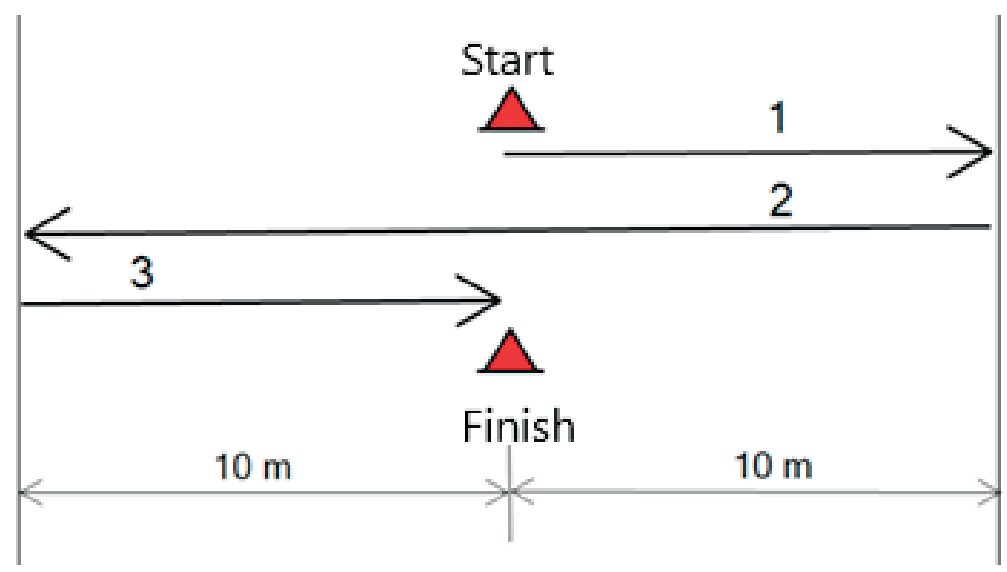

Figure 1. Test scheme for running / skating at $40 \mathrm{~m}$ with changes of direction

\section{Statistical methods}

With respect to quasi-experiment research with relatively small intentionally selected files, instead of the standard two-way ANOVA, we assessed differences in mean values using effect size theory (ES; Cohen, 1988; Hopkins, 2016). When summarizing the data, we used Microsoft Excel software, we processed the statistical data in the statistical program Statistica (version 13.2), or using the statistical calculator Social Science Statistics (https://www.socscistatistics.com/). To assess the differences in mean values, we used the effect size (ES) index $\mathrm{d}$, which can be interpreted according to Cohen $(1988)$ as small $(d=0.20)$, medium $(d=0.50)$ or large $(d=0.80)$, Hopkins (2002) uses for values $\mathrm{d}<0.2$ interpretation "trivial". 


\section{RESULTS}

Figure 2 graphically shows the results of a $40 \mathrm{~m}$ running speed test with changes in the direction of the experimental (EXP) and control (KO) sets.

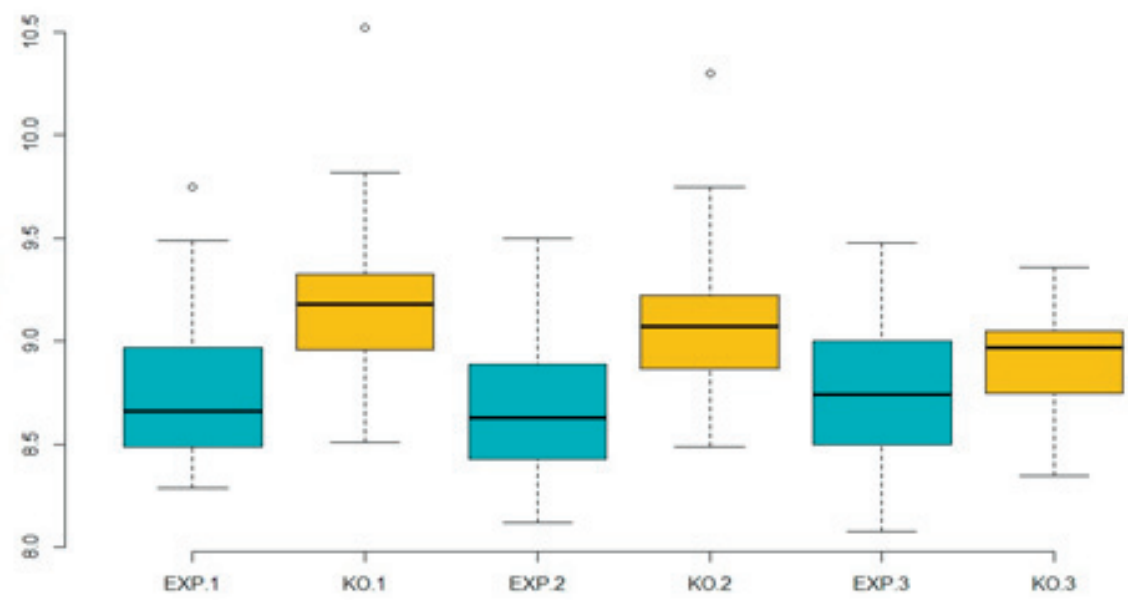

Figure 2. Results of running speed of experimental and control set in test $40 \mathrm{~m}$ with changes of direction

Note: EXP 1 = experimental file, input testing, EXP 2 = experimental file, output testing, EXP 3 = experimental file, post-experimental testing, $\mathrm{KO} 1=$ control file, input testing, $\mathrm{KO} 2=$ control file, output testing, $\mathrm{KO} 3=$ control set, post-experimental testing

Table 3 shows the results of the $40 \mathrm{~m}$ running speed test with changes in the direction of the experimental and control sets and their statistical assessment. Assessment of the significance of differences in mean values (M) between input testing (EXP 1), output testing (EXP 2) and postexperimental testing (EXP 3) of the experimental set, as well as between input testing (KO 1), output testing (KO 2) and post-experimental testing (KO 3) of the control file was performed using the effect size (ES) index d.

Table 3. Test of running speed at $40 \mathrm{~m}$ with changes of direction (s) - files EXP and KO

\begin{tabular}{|c|c|c|c|c|c|c|}
\hline $\operatorname{EXP}(n=18)$ & $\mathbf{M}$ & SD & Min & Max & $\operatorname{EXP} 2(d)$ & $\operatorname{EXP} 3(d)$ \\
\hline EXP 1 & 8.75 & 0.39 & 8.29 & 9.75 & 0.16 & 0.03 \\
\hline EXP 2 & 8.69 & 0.38 & 8.12 & 9.50 & & 0.13 \\
\hline EXP 3 & 8.74 & 0.37 & 8.08 & 9.48 & & \\
\hline KO $(n=15)$ & $\mathbf{M}$ & SD & Min & Max & KO $2(d)$ & KO $3(d)$ \\
\hline KO 1 & 9.18 & 0.49 & 8.51 & 10.52 & 0.15 & $0.75^{\star}$ \\
\hline KO 2 & 9.11 & 0.45 & 8.49 & 10.30 & & $0.61^{\star}$ \\
\hline KO 3 & 8.88 & 0.28 & 8.35 & 9.36 & & \\
\hline
\end{tabular}

Notes: $\mathrm{EXP}=$ experimental file; $\mathrm{KO}=$ control file; $\mathrm{n}$ - number of subjects; $\mathrm{M}=$ mean; $\mathrm{SD}=$ standard deviation; Min = minimum value; $M a x=$ maximum value; $d=$ effect size index $\left({ }^{*}=\right.$ medium $)$

Significant differences were found between the results of the running speed tests of the EXP and $\mathrm{KO}$ files both in the pretest (EXP $1 \mathrm{x} \mathrm{KO} 1, \mathrm{~d}=0.97$, large) and in the postest (EXP $2 \mathrm{x}$ 
$\mathrm{KO} 2, \mathrm{~d}=1.01$, large) in favor of the group EXP, in post-experimental testing, the differences can be evaluated as small, again in favor of the EXP set (EXP $3 \times \mathrm{KO} 3, \mathrm{~d}=0.43$, small). These differences found between the EXP and KO sets successively during the 1st, 2nd and 3rd testing $(0.43 ; 0.42 ; 0.14 \mathrm{~s})$ were always in favor of the EXP set. It is obvious that even after 8 weeks of intervention (EXP group) the difference between the two groups hardly changed (EXP $2 \times \mathrm{KO} 2$; $\mathrm{dif}=0.01 \mathrm{~s}$ ). It is therefore not possible to compare the effect of plyometric exercises between the EXP2 and KON2 sets, but only between the EXP 1 - EXP 2 sets, resp. EXP 2 - EXP 3. During the 16-week time period, the following character of the results of the EXP set was gradually recorded in three tests: $\mathrm{M}=8.75-8.69-8.74(\mathrm{~s})$. After completing the plyometric exercises, there was only an insignificant improvement in the level of mean values of the running speed test results (dif $=0.06 \mathrm{~s})$, the effect of the intervention was not proven $(\mathrm{d}=0.16$, trivial). In postexperimental testing (EXP 3), only a slight decrease in the level was found both compared to the 1 st test EXP $1(\mathrm{~d}=0.03$, trivial $)$ and compared to the 2 nd test $(\mathrm{d}=0.13$, trivial $)$. Thus, the effect of plyometric exercises on the improvement of the running speed level was not demonstrated in the EXP group. The test results for the KO group had the following character in the 16-week time period: $M=9.18-9.11-8.88$ (s). While there was only a slight improvement between the results of the pretest $(\mathrm{KO} 1)$ and the postest $(\mathrm{KO} 2)(\mathrm{d}=0.15$, trivial), there was a significant improvement in both the pretest $(\mathrm{d}=0.75$, medium) and the post-experimental testing (KO 3 ). and posttest $(\mathrm{d}=0.61$, medium). This can be attributed to influences that are difficult to identify, such as the number of matches played in the period under review.

Figure 3 graphically shows the results of a skating speed test at $40 \mathrm{~m}$ with changes in the direction of the experimental (EXP) and control (KO) sets.

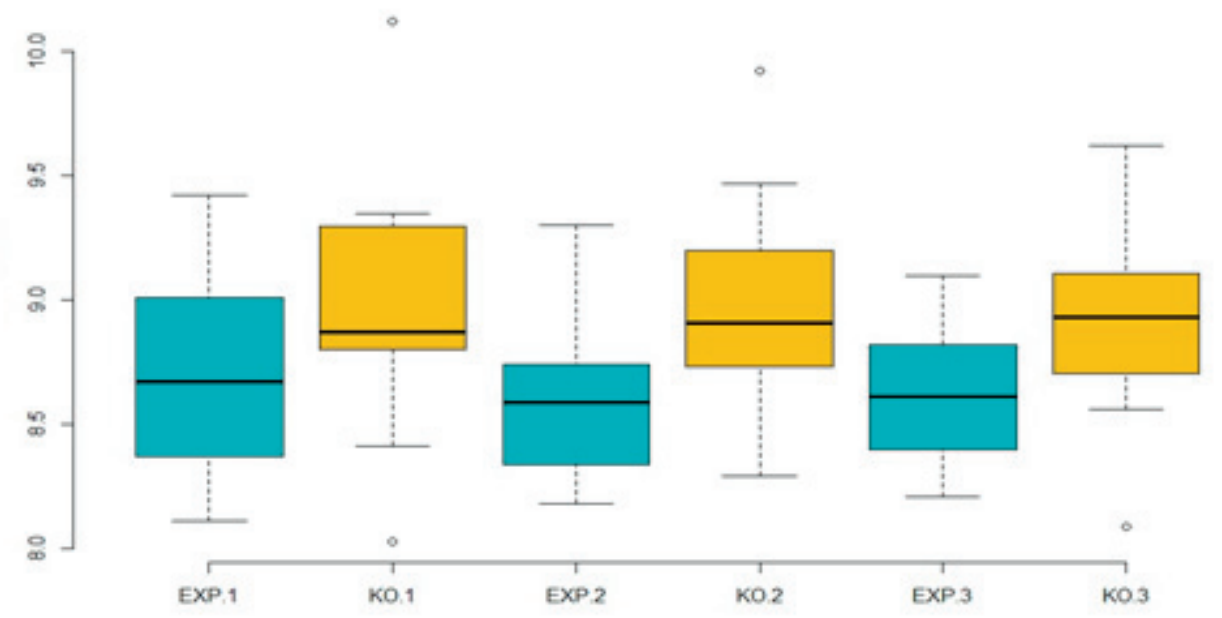

Figure 3. Results of the skating speed of the experimental and control set in the test $40 \mathrm{~m}$ with changes of direction

Note: EXP 1 = experimental file, input testing, EXP 2 = experimental file, output testing, EXP $3=$ experimental file, post-experimental testing, $\mathrm{KO} 1$ = control file, input testing, $\mathrm{KO} 2=$ control file, output testing, $\mathrm{KO} 3=$ control set, post-experimental testing

Table 4 shows the results of the skating speed test at $40 \mathrm{~m}$ with changes in the direction of the experimental and control set and their statistical assessment. Assessment of the significance of differences in mean values (M) between input testing (EXP 1), output testing (EXP 2) and 
post-experimental testing (EXP 3) of the experimental set, as well as between input testing (KO 1), output testing (KO 2) and post-experimental testing ( $\mathrm{KO} 3$ ) of the control file was performed using the effect size (ES) index $\mathrm{d}$.

Table 4. Skating speed test at $40 \mathrm{~m}$ with changes of direction (s)

\begin{tabular}{lcccccc}
\hline EXP $(n=18)$ & M & SD & Min & Max & EXP 2 $(d)$ & EXP 3 $(d)$ \\
\hline EXP 1 & 8.70 & 0.39 & 8.22 & 9.42 & 0.27 & 0.27 \\
EXP 2 & 8.60 & 0.34 & 8.18 & 9.30 & & 0.03 \\
EXP 3 & 8.61 & 0.28 & 8.21 & 9.30 & & KO 3 $(d)$ \\
\hline KO $(n=15)$ & M & SD & Min. & Max. & KO $(d)$ & 0.17 \\
KO 1 & 8.96 & 0.48 & 8.03 & 10.12 & 04 & 0.13 \\
KO 2 & 8.94 & 0.42 & 8.29 & 9.92 & & KO \\
KO 3 & 8.89 & 0.34 & 8.09 & 9.62 & & \\
\hline
\end{tabular}

Notes: $\mathrm{EXP}=$ experimental file; $\mathrm{KO}=$ control file; $\mathrm{n}$ - number of subjects; $\mathrm{M}=$ mean; $\mathrm{SD}=$ standard deviation; Min = minimum value; Max = maximum value; $\mathrm{d}=$ effect size index $(\mathrm{d}<0.2=$ trivial; $\mathrm{d}<0.5=$ small $)$

In the skating speed test, there were between the mean values of the EXP and KO sets both in the pretest (EXP $1 \times \mathrm{KO} 1, \mathrm{~d}=0.60$, medium) and in the postest (EXP $2 \times \mathrm{KO} 2, \mathrm{~d}=0.89$, large) and in post-experimental testing (EXP $3 \times \mathrm{KO} 3, \mathrm{~d}=0.90$, large) significant differences in mean values were found. These differences found between the EXP and $\mathrm{KO}$ sets successively during the 1 st, 2 nd and 3 rd tests $(0.26,0.34,0.28 \mathrm{~s})$ were lower in the running speed test, but always in favor of the EXP set. It is obvious that even after 8 weeks of intervention (EXP set) the difference between the two sets hardly changed (EXp $2 \times \mathrm{KO} 2$; dif $=0.08 \mathrm{~s})$. It is therefore difficult to compare the effect of plyometric exercises between the EXP2 and KON2 groups, but only between the EXP 1 - EXP 2, resp. EXP 2 - EXP 3. Again, it is difficult to compare the effect of plyometric exercises between the sets EXP2 and KON2, but only between the groups EXP 1 EXP 2, respectively. EXP 2 - EXP 3. During the 16-week time period, the following character of the results of the EXP set was gradually recorded in three tests: $M=8.70-8.60-8.61$ (s). After completing the plyometric exercises, only a small effect of the intervention was demonstrated $(\mathrm{d}=0.27$, small), in post-experimental testing (EXP 3$)$ only a small decrease in levels was found compared to the initial testing EXP $1(\mathrm{~d}=0.27$, small) and none compared to the 2 nd testing EXP $2(\mathrm{~d}=0.03$, trivial). Thus, only a small effect of plyometric exercises on the improvement of skating speed was demonstrated in the EXP group. The test results for the KO group had the following character in the 16-week time period: $M=8.96-8.94-8.89$ (s). Thus, there was only a slight improvement between the results of pretest $(\mathrm{KO} 1)$ and postest $(\mathrm{KO} 2)(\mathrm{d}=0.04$, trivial), with post-experimental testing $(\mathrm{KO} 3)$ there was a slight improvement compared to pretest $(\mathrm{d}=$ 0.17 , trivial $)$ and and posttest $(\mathrm{d}=0.13$, trivial $)$.

\section{DISCUSSION}

In a 40 meter forward skating test with changes of direction, authors such as Mascaro (1992), Behm et. al. (2005) and Blanár (2019) dealt with similar tests such as sprint with changes of direction to $4 \times 10 \mathrm{~m}$, sprint with changes of direction to $4 \times 9 \mathrm{~m}$, Pro agility test at 5-10-5 yards, test of skating at 5-7-5 m or Weave agility test in different age categories. Behm et.al. (2005) worked on research with thirty hockey players with an average age of 19 years. The aim of his work was to find out what effect balance and speed-strength exercises have on the stability of players and 
maximum speed in skating. He tested speed, speed with changes of direction, stability during braking and stability during rotation. He found that significant differences were recorded at 0.05\% statistical significance, especially in equilibrium tests. In his study, Mascaro (1992) tested sixteen professional hockey players after the end of the season with an average age of 23.3 years, with only 9 players included in the final evaluation of the results. In the dry he tested a sprint for 40 yards, a vertical jump and a long jump from the spot. There was only one test on the ice, a sprint for 60 yards. The biggest statistical dependence was shown between a vertical jump and skating at 60 yards, probably because ice hockey players train more on-ice than on dry land. In the youth category (U18) Blanár (2019) measured an average time of $4.90 \pm 0.22 \mathrm{~s}$ in the agility test for 5-10-5 yards, in the same test focused on the speed of skating, the average performance was $4.69 \pm 0.22 \mathrm{~s}$. the results in tests with changes in direction in running speed and skating showed that players are faster in skating than in running, which is in line with our results in the EXP file and partly in the KO file, where there was better performance in two measurements in skating speed and in one at running speed (about 0.01 s). Novák (2019) worked on research with 14 ice hockey players with an average age of 14.8 during the current season from September to December 2017. He divided the players into two experimental groups. In both groups, in addition to the classic training program, players completed 3 training units for 20-30 minutes focused on agility. In the first group, players performed agility training on ice twice a week for 4 weeks, followed by a 2 -week rest period, followed by a 4 -week off-ice agility training. In the second group, the program was performed in reverse, 4 weeks of agility training off the ice, two weeks of rest and 4 weeks of agility training on ice. The tests consisted of an accelerating skating of 6.10 meters, a skating of 35 meters, a S corner test, a braking test, a weave agility test and a reaction test. His study showed that one or the other program of including training units for the development of agility of players in puberty had a positive effect in all tested skating tests, although agility training directly on ice had a slightly more favorable effect in terms of reactive agility. Its results do not agree with ours, because in our country the effect of plyometric exercises was not demonstrated either on ice or on dry land. Lee, et. al (2014) worked with 20 ice hockey players aged 18-22 years in research, where he found that a 12-week plyometric exercise program had a positive effect on the skating speed of players with changes of direction in the experimental group in $5 \times 18 \mathrm{~m}$ and line drill tests. In the control group, players also improved in the $5 \times 18 \mathrm{~m}$ test but significantly worsened in the line drill test. Its results do not match ours. The differences compared to our research were in the duration of the plyometric exercise program, the age category as well as in the effectiveness of the program.

\section{CONCLUSION}

Based on the analysis of the results of the quasi-experiment, it was shown that the training protocol in this form does not affect the improvement of running speed and skating speed in ice hockey. Significant differences between the experimental (EXP) and control (KO) sets in favor of the EXP set were found between the results of the running speed and skating speed tests, both in the pretest and in the postest. The EXP group did not show the effect of plyometric exercises on the improvement of the level of running speed and only a small effect on the improvement of the level of skating speed. With regard to the published knowledge about the influence of plyometric exercises, it would therefore be appropriate to modify the training protocol and verify its effectiveness in performance-balanced sets. 


\section{References}

Behm, D. G., Wahl, M. J., Button, D. C., Power, K. E., \& Anderson K. G. (2005). Relationship between hockey skating speed and selected performance measures. Journal of Strength and Conditioning Research, 19(2), 326-331.

Blanár, M. (2019). Faktory vplývajúce na rýchlost'korčulovania v ladovom hokeji. Trenčín: HK Dukla Trenčín n. o.

Boyl, M. (2016). New functional training for sports. Champaign: Human Kinetics.

Cohen, J. (1988). Statistical power analysis for the behavioral sciences (2nd ed.). Hillsdale. NJ: Erlbaum.

Dæhlin, T. E., Haugen, O. C., Haugerud, S., Hollan, I., Raastad, T., \& Rønnestad, B. R. (2017). Improvement of Ice hockey players on-ice sprint with combined plyometric and strength training. International journal of sports physiology and performance, 12(7), 893-900. DOI: https://doi.org/10.1123/ijspp.2016-0262

Hansen, D., \& Kennelly, S. (2017). Plyometric anatomy. Champaign: Human Kinetics,

Haukali, E., \& Tjelta, L. I. (2015). Correlation between off-ice variables and skateing performance among young male ice hockey players. International Journal of Applied Sports Science, 27(1), 26-32.

Hopkins, W. (2016). A new view of statistics. Retrieve from http://www.sportsci.org/resource/stats/index.html

Chu, D. (1998). Jumping into plyometric. Champaing: Human Kinetics.

Jebavý, R., \& Hojka, V. (2017). Kondiční trénink ve sportovních hrách. Praha: Grada publishing.

Joyce, D., \& Lewindon, D. (2014). High performance training for sports. Champaign: Human Kinetics.

Lockwood, K. L., \& Brophey, P. (2008). The Effect of a Plyometrics Program Intervention on Skating Speed in Junior Hockey Players. The Sport Journal, 41(2). https://thesportjournal.org/article/the-effect-of-a-plyometrics-program-interventionon-skating-speed-in-junior-hockey-players/

Lee, Ch., Lee, S., \& Yoo, J. (2014). The Effect of a Complex Training Program on Skating Abilities in Ice Hockey Players. Journal of Physical Therapy Science, 26(4), 533-537. doi: 10.1589/jpts.26.533

Mascaro, T., Seaver B. L., \& Swanson, L. (1992). Prediction of Skating Speed with Off-Ice Testing in Professional Hockey Players. Jurnal of Orthopedic and Sports Physical Therapy, 15(2), 92-98. https://www.jospt.org/doi/10.2519/jospt.1992.15.2.92

Novák, D., Lipinska, P., Roczniok, R., Spieszny, M., \& Stastny, P. (2019). Off-Ice Agility Provide Motor Transfer to On-Ice Skating Performance and Agility in Adolescent Ice Hockey Players. Journal of Sports Science and Medicine, 18(4), 680-694. https:// www.ncbi.nlm.nih.gov/pmc/articles/PMC6873137/

Owen, A., \& Della, A. (2016). Football Conditioning a Modern Scientific Approach: Fitness Training - Speed \& Agility - Injury Prevention. Alex Fitzgerald: Soccertutor.com.

Perič, T., \& Dovalil, J. (2010). Sportovní trénink. Praha: Grada Publishing.

Skahan, S. (2016). Total hockey training. Champaign: Human Kinetics.

Tóth, I. (2010). Tréner ladového hokeja. Bratislava: SZLH, FTVŠ UK. 